\title{
Economic Risk Analysis in Postsecondary Education: Local Perspective
}

\author{
Elisa Queenan ${ }^{1}$, Brian D. Street ${ }^{2}$ \\ Porterville College ${ }^{1}$, California State University ${ }^{2}$ \\ United States
}

\begin{abstract}
The cost of postsecondary education continues to increase, contributing to elevating federal loan demand, but importantly to debt, equaling $\$ 1.5$ trillion in the US. The purpose of this study was to examine the economic risk associated with the undergraduate programs of Bakersfield College $(B C)$ and California State University, Bakersfield (CSUB) on their local labor market of Kern County. Specifically, assessing risk exposure to individuals by educational attainment. Despite both being public institutions, serving a student body of underrepresented minorities, the loan default rates of each institution differed; six-year mean rates were $23.7 \%$ at BC, but only $7.4 \%$ at CSUB between 2009 to 2014. Risk is highest while a student is in school but diminishes when a degree is earned. The significance of this study is the creation of an economic risk analysis that stakeholders, as well as economic and academic policy makers, can use to provide a tool to understand how the individual, the institution and the local labor market are affected by the increasing cost of PE, especially with the growing student loan crisis associated with the pursuit of PE. A similar analysis could be carried out in different counties or grouped for state and national perspectives.
\end{abstract}

\section{Introduction}

With the continual rise in the cost of postsecondary education (PE) the economic value associated with the pursuit and attainment of an undergraduate degree is receiving increased attention. Student loan debt is on the rise, totaling $\$ 1.5$ trillion in the US [13]. PE is positively correlated with higher earnings [2, 23], better health outcomes [4, 24], and less government dependency $[3,6,29]$, but the time to degree, major chosen and debt incurred may create an economic risk associated with the pursuit of PE. When students fail to graduate, fail to enter the labor market and/or default on their loans, there can be economic loss; the student loses out on the opportunity for increased wages, the institution is penalized for the student's default and the local economy will fail to see an increase in spending and taxes. Economic risk is unavoidable whether the individual pursues postsecondary education or foregoes it, however, the risk and reward of both options can vary immensely. This risk and reward relationship assume the longterm benefits of an earned postsecondary degree, as stated above, exceed the economic risk of the journey. The pursuit of a PE degree with debt does not in itself negate any long-term benefits, the concern would be with PE debt, having not completed the degree or if left under-employed; federal, state and local agencies and institutions should look to pursue economic and educational policy that ultimately benefits human capital to satisfy labor market demand and desire for economic growth. The purpose of this research was to create a method for assessing the economic risk associated with PE for students, the institution and the local economy. In this case study design the two postsecondary institutions chosen were, Bakersfield College (BC) and California State University, Bakersfield (CSUB), both are Hispanic Serving Institutions (HSI), in Kern County (KC), California. The following objectives guided the analysis: investigate the expected economic risk for an individual graduating from BC or CSUB with an associate or bachelor degree, respectively, compared to the non-postsecondary educated individual between 2009-2014.

\section{Literature}

In education there are two primary areas of risk in pursuing PE, market and specific risk. A variety of macro conditions, such as, inflation, interest rates, unemployment, and poverty level influence market risk. These are not risk elements the student or the institution has influence over. Specific risk, a combination of institutional risk and individual risk, however, is within the sphere of influence and is examined within the literature. This research looked specifically at institutional expense per full-time equivalent (FTE) student, institutional graduation rates, market correlation, and institutional cohort default rates (CDR). Each of these categories are intertwined with the other.

\subsection{Instructional expense per FTE student}

Expenses related to instruction are generally the highest expense at public institutions [25]. Research conducted by Webber and Rogers [32] and Ishitani and McKitrick [22] show these expenses play an important role in higher student retention and that they have a negative relationship with student loan defaults. Retention is important to both the institution and the student because it leads to degree completion. 


\subsection{Institutional graduation rate}

The literature has found the most important institutional factor to mitigating risk against student loan default comes down to degree completion, which is the macro version of educational attainment at the student level. Research conducted by Herr and Burt [20], Gross, Cekic, Hossler, and Hillman [18] and Webber and Rogers [32], Ishitani and McKitrick [22], and Fincher [15] all confirm the importance of degree completion for both the institution and the individual in mitigating economic risk. Major choice and degree completion greatly influence occupational opportunities.

\subsection{Market correlation}

Choice of major is impactful for students mitigating risk in the labor market, but the real crux comes down to demand. Several studies have found those who earned a degree in business, engineering, computer, physical sciences, architecture, humanities, and math, had both more interviews after graduation and higher incomes than majors other than those listed above $[5,8,9,10]$. The reason these majors resulted in more interviews and a higher income is due to demand. There were more jobs available in those fields at that time. Aligning degree completion with labor market demand is valuable in mitigating economic risk which will further impact student loan default.

\subsection{Institutional cohort default rate}

There are several factors which contribute to student loan default. These factors stretch the length of individual and institutional characteristics. Aside from the factors listed above, race/ethnicity $[17,18,19,20,27,33,34]$, age and dependents $[31,21,27,34]$, and socio-economic status $[21,12,16,28]$ were all influential in whether a student defaulted on their loan. Aside from the factors associated with loan default, the risk that is guaranteed when a student defaults is just as important. If an individual default on their federal student loan, the entire loan becomes due immediately (acceleration) and all deferment or forbearance options are withdrawn. If the loan is sent to a private collection agency the individual can have $15 \%$ of their disposable wages garnished or be sued by the U.S. Department of Justice [14].

\subsection{Theoretical framework}

The gap in the literature this research will address is how the combination of these risk factors influence the economic impact of postsecondary, public, undergraduate education, on the individual, the institution and the local economy. The following offers a theoretical framework for the variables assessed in the risk model. The frameworks utilized are the Human Capital (HC) Theory and Modern Portfolio Theory (MPT). Choosing to pursue debt to earn a postsecondary degree forces students to make decisions with weightier cost-benefit implications, than if no debt was involved. HC Theory [4], assumes a rational decision is made through the process of weighing expected costs and benefits. Individuals will pursue an education so long as the marginal benefits exceed the marginal costs. Essentially, HC Theory affirms the idea the debt to pursue an education is worth the trade-off for growth in long-term earnings, both monetary and non-monetary, with the expectation there will be a positive rate of return. These decisions can be weighed using Modern Portfolio Theory (MPT), which was pioneered by Harry Markowitz originally as Portfolio Theory in 1952. MPT is a theory on how risk-averse investors can maximize returns based on market risk. It assumes investors are risk averse and will only take on an investment if there is a risk premium in addition to the reward.

\section{Methods}

Modern Portfolio Theory (MPT) was used to ground the examination of associated economic risk. Specifically, the relationship to risk was examined considering: (1) market characteristics in Kern County, (2) the individual and (3) the institution of higher education. The purpose of applying MPT is to quantify predictable returns through the acknowledgement of economic risk. There are two facets of economic risk accounted for in MPT: (1) market risk and (2) specific risk [1].

\section{Total risk $=$ market risk + specific risk}

Specific risk examines both institutional and individual risk. Institutional risk incorporates market correlation (how well the degrees issued align with the local labor market), institutional graduation rate, institutional cohort default rate, and instructional expense per full-time equivalent (FTE) student. Individual risk primarily centers on unemployment and poverty and the probability of an individual experiencing both based on their educational attainment and the region in which they reside. Each facet of economic risk: market (geographical), institutional, and individual were examined in their separate spheres and then combined to acquire total risk.

\subsection{Market risk}

Market (geographical) risk cannot be controlled or avoided, by either the institution or the individual. 
Market economic risk was examined in this study using unemployment rates, inflation, real per capita income, the local poverty rate and demographic changes. Inflation was chosen as a gauge for price stability, real per capita income, as an overview for individual economic growth, unemployment and the poverty rate to assess working and living standard risk, and head of house speaking in English to examine changes in demographics. All variables apart from inflation were normalized with national data to compare risk exposure. The higher the numeric value for market risk, the greater the risk exposure compared to national risk. Thus, a negative risk equates to less risk exposure than what was experienced at the national level and a positive risk value equates to more risk exposure than the national level.

For this investigation, the model defined market risk with the following variables:

$\mathrm{i}=$ Inflation

$U_{r}=$ Seasonally adjusted unemployment rate in the region ( $r$ ) under investigation, in this case study, Kern County

$U n=$ Seasonally adjusted national unemployment rate

$r p c I=$ Real per capita Income

$P R=$ Poverty rate

$n=$ nation

$r=$ region

Market (geographical) risk is calculated through the following model:

$\Delta i-\left(U n-U_{r}\right)-\% \Delta\left(r p c I_{n}-r p c I_{r}\right)-\left(P R n-P R_{r}\right)-\% \Delta \frac{H H E n}{H H E_{r}}$

\subsection{Institutional risk}

Institutional economic risk incorporated how well the top institutional degrees align with the local labor market (market correlation), institutional graduation rate, institutional cohort default rate, and instructional expense per full-time equivalent (FTE) student.

Specific institutional risk is defined with the following variables:

$I_{g}=$ Institutional graduation rate

$C D R=$ Institutional cohort default rate (at $150 \%$ time)

$\mathrm{Mc}=$ Market correlation $^{1}$

IFTE = Instructional expense per FTE

Institutional risk is calculated by

\footnotetext{
${ }^{1}$ Kendall's Tau-b correlation between the top degrees supplied at $\mathrm{BC}$ and CSUB compared to the demand for occupations in the Kern County labor market. This is a nonparametric analysis with $p$
}

$$
\left(1-I_{g}\right)+\left(1-M c_{b c}\right)-\% \Delta I F T E_{b c}+C D R_{b c} j t-3
$$

The variable $b$ is BC, $c$ is CSUB, $j$ either the 2 or 3year CDR and $t$ for time in years.

A risk rate of zero would equal no institutional risk; degrees issued align perfectly with labor market demand, all students graduate by $150 \%$ time ( 3 years for BC and 6 years for CSUB); no students default on their loans and instructional expense per FTE maintains a positive linear relationship to enrollment.

\subsection{Individual risk}

Individual economic risk centered on exposure to unemployment and poverty, in the region where the student lives.

$$
\left[\left(U n-U_{r}\right)\left(w p_{a b n}\right)\right]-\left[\left(P R_{N}-P R_{r}\right)\left(w p_{a b n)}\right]\right.
$$

$w p$ is the weighted probability of an individual being subjected to unemployment or poverty based off educational attainment. The subscript $a$ is for an earned associate degree, $b$ for an earned bachelors and $n$ for no PE.

To assess the probability of this risk the unemployment and poverty rate were averaged by educational attainment (i.e., high school completion, some college, no bachelor's degree and bachelor's degree or higher) and divided by the average rate for the population.

$$
\frac{\text { average } U P R_{\text {abnt }}}{\text { average } U n P R_{t}}
$$

The higher the numerical value the greater the risk of exposure to unemployment and poverty. The lower the numerical value the less vulnerable an individual is to that exposure, with a value of zero equating to no probability of exposure to unemployment and poverty.

\subsection{Total risk}

Total economic risk was the aggregate exposure to each risk component. Specifically, total risk takes into consideration market (geographical) risk, institutional risk and individual risk, depending on the where the person is in their educational pursuits. A total risk value of zero would equate to risk equivalent to that found with national risk. A negative risk equals less risk than found nationally and a positive risk means there are factors which increase the risk or opportunity cost of pursuing PE relative to the nation. 


\section{Results}

Economic risk is multilayered and complex. Whether an individual chooses to pursue PE or not, there is an economic risk being undertaken, which is why it is valuable to compare the expected risk for an individual graduating from BC or CSUB to the non$\mathrm{PE}$ individual.

\subsection{Market risk}

The market risk in Table 1 demonstrates the change in risk associated with the local economy under investigation. From 2009-2011 Kern County saw an extensive growth in the level of risk. Market risk for Kern County declined from 2012-2013 and then increased again in 2014.

Table 1. Market risk for Kern County, 2009-2014

\begin{tabular}{lc}
\hline Year & Market (geographical) risk \\
\hline 2009 & -1.08 \\
2010 & 0.90 \\
2011 & 2.16 \\
2012 & 1.88 \\
2013 & 0.91 \\
2014 & 1.40 \\
\hline
\end{tabular}

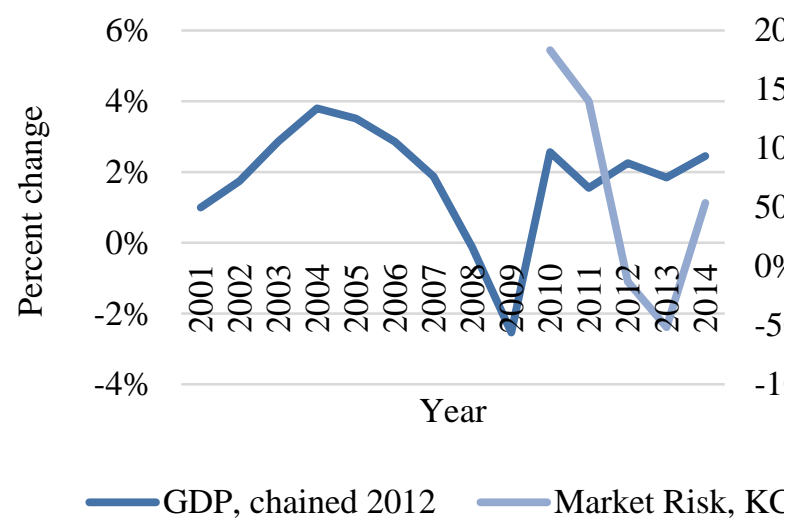

Figure 1. Percent change in Gross Domestic Product and Kern County market risk

When we examine local market risk and percent change of national Gross Domestic Product in the US, see Figure 1, an approximate 12-18 month lag between national and county impact is apparent with the peak of the Great Recession in late 2009 and the peak of risk in Kern County at the start of 2011.

\subsection{Institutional risk}

Institutional risk included the market correlation between labor market demand and degrees issued, the institutional graduation rate, the institutional cohort default rate, and instructional expense per full-time equivalent (FTE). From 2009 to 2014, the institutional risk for $\mathrm{BC}$ fluctuated between 1.76 and 2.00; from 1.48 and 1.63 for CSUB, see Table 2. BC's vacillation in risk varied $13.63 \%$ at its widest point and $10.13 \%$ for CSUB. As an institution, BC experienced, on average, $20 \%$ more economic risk than CSUB.

Table 2. Institutional risk, 2009-2014

\begin{tabular}{lll}
\hline Year & BC & CSUB \\
\hline 2009 & 1.90 & 1.56 \\
2010 & 1.76 & 1.63 \\
2011 & 1.81 & 1.48 \\
2012 & 1.87 & 1.53 \\
2013 & 1.88 & 1.58 \\
2014 & 2.00 & 1.55 \\
\hline
\end{tabular}

\subsection{Individual risk}

Individual economic risk investigated the probability an individual with no PE education, an associate degree or a bachelor's degree, would experience unemployment and poverty, specific to where they reside. Table 3 shows the approximate risk experienced by education attainment. Individual economic risk declined as educational attainment advanced; a person with no PE 9\%; an individual with an associate degree $7 \%$ and an individual with an earned bachelor's degree $2 \%$.

Table 3. Individual risk by educational attainment specific to Kern County

\begin{tabular}{llll}
\hline Year & Non-PE & Associate's & Bachelor's \\
\hline 2009 & 0.09 & 0.07 & 0.02 \\
2010 & 0.08 & 0.06 & 0.02 \\
2011 & 0.08 & 0.06 & 0.02 \\
2012 & 0.09 & 0.07 & 0.02 \\
2013 & 0.09 & 0.07 & 0.02 \\
2014 & 0.09 & 0.07 & 0.02 \\
\hline
\end{tabular}

\subsection{Total risk}

Total economic risk which incorporated market economic risk, institutional economic risk and 
individual economic risk declined by educational attainment; for the individual with no PE $105 \%$, an earned associate's degree $102 \%$, and an earned bachelor's $98 \%$. However, the most risk is born by those currently in PE, the BC student at $292 \%$ and the CSUB student at $260 \%$, see Table 4.

Table 4. Total risk by educational pursuits and attainment, specific to Kern County

\begin{tabular}{crrrrr}
\hline & & & & \multicolumn{3}{c}{ Student } \\
at \\
Year & Non-PE & $\begin{array}{c}\text { Student } \\
\text { at BC }\end{array}$ & Associate's & CSUB & Bachelor's \\
\hline 2009 & -1.06 & 0.84 & -1.08 & 0.49 & -1.13 \\
2010 & 0.92 & 2.68 & 0.90 & 2.55 & 0.86 \\
2011 & 2.17 & 3.98 & 2.15 & 3.65 & 2.11 \\
2012 & 1.90 & 3.77 & 1.88 & 3.43 & 1.83 \\
2013 & 0.93 & 2.81 & 0.91 & 2.51 & 0.86 \\
2014 & 1.42 & 3.42 & 1.40 & 2.97 & 1.35 \\
$6-y r$ & $\mathbf{1 . 0 5}$ & $\mathbf{2 . 9 2}$ & $\mathbf{1 . 0 2}$ & $\mathbf{2 . 6 0}$ & $\mathbf{0 . 9 8}$ \\
ave. & & & & & \\
\hline
\end{tabular}

\section{Discussion}

To equip students and postsecondary institutions with the tools needed to address areas of economical vulnerability it is important to assess the economic risk for an individual graduating with a PE degree compared to the non-postsecondary educated individual. The implication of increased economic risk is important to understand; while the degree is in progress the student becomes more economically vulnerable than their non-PE counterpart. The three most important areas to which support this vulnerability are: degree alignment with the local labor market, time to graduation and job placement $[8,15,26]$. While individual exposure to unemployment and poverty will never be zero, policymakers work to limit its impact. The impact of unemployment and poverty vary based off educational attainment and the region the individual is living, and at least in Kern County, the value of degree completion cannot be understated.

\subsection{Market risk}

Acknowledging there is little BC and CSUB can do to decrease the risk exposure of Kern County is important, but it is not fully complete. Making degree alignment (market correlation) a priority, BC and CSUB can in fact, mitigate their student's exposure by equipping them with the degrees most likely to thrive when market risk increases. This strategic move will in fact have an impact on the market risk of Kern County and would generally have utility regardless of location. If both institutions work strategically and intentionally to create a labor supply that meets projected market demand when economic fluctuations occur, the risk will be less likely to increase since a larger portion of the market is academically equipped to meet the demand need. There is a symbiotic relationship between BC, CSUB and Kern County, the importance of which appears to be undervalued. Market risk is imperative to understanding the specific risk found in examining institutional and individual exposure.

\subsection{Institutional risk}

Institutional risk is that risk which is created by the institution. This analysis examines how well the top institutional degrees align with the local labor market (market correlation), the institutional graduation rate, instructional expense per FTE student and the institutional cohort default rates. On average, BC experienced $20 \%$ more risk than CSUB during this time. It is likely $\mathrm{BC}$ will maintain a higher risk exposure than CSUB because of the nature of their mission and vision. $\mathrm{BC}$ is a community college, open to anyone within the community. Community colleges have historically been a resource for those who wish to explore education without a solid understanding of what the individual wishes to major in. While this mindset is transitioning and community colleges are being held accountable to higher outcome standards to ensure more students are earning a PE award, transferring to a four-year institution and earn a living wage [7], community colleges will continue to maintain their commitment to serve the community. In addition, since it is the mission of community colleges to serve the community there are no admissions criteria with which to factor out those individuals who are unprepared for PE. Furthermore, the degrees offered by BC offer a lower median wage, $\$ 33,755^{2}$ at graduation than those obtained at CSUB, $\$ 55,827$ which contributes to the risk association the individual experiences to unemployment and poverty [30].

Both institutions of higher education have responsibilities to meet the labor market needs in Kern County, as benefactors of public funds, and to the student who has chosen to align themselves with the institution. This can be challenging; labor market demand shifts quickly whereas the ability to modify curriculum and degrees can be more cumbersome and a therefore a slower process. The most critical point to reiterate is that degree alignment with labor market demand equals more balance between labor market demand and supply, thus leading to individuals being academically equipped to meet the demands of the occupations for which they were trained. BC and CSUB carry varying responsibility into the supply they should be providing for the local market. BC can focus on entry-level occupations; CSUB, depending 
on the major, primarily technical or advanced occupations.

\subsection{Individual risk}

The risk of unemployment and poverty vary with educational attainment. As expected, the risk associated with an individual with no PE is higher than that of a person who holds a PE degree. Earning an associate degree decreased the risk of unemployment and poverty by $-24 \%$. Earning a bachelor's degree decreased this risk further a total of $-73 \%$ from the non-PE individual. The implications of this are important for policymakers and institutions of higher education. Completed PE and the subsequent decreased exposure to unemployment and poverty, can result in the strengthening of individual economic security and an increase of monetary injections back into the economy.

\subsection{Total risk}

Total risk takes into consideration market risk, the specific risk of the institution and the specific risk of the individual's educational attainment, in the region under investigation. The non-PE individual is not exposed to the institutional risk, but also misses out on the subsequent rewards, monetary and nonmonetary, from completing a degree. It is important to note, risk carries complicated relationships for the individual. This risk comes from places the student may not realize when pursuing PE. In addition to being exposed to risk from various areas it is important to acknowledge that risk accumulates as it moves from the market to the institution to the individual (see Figure 2).

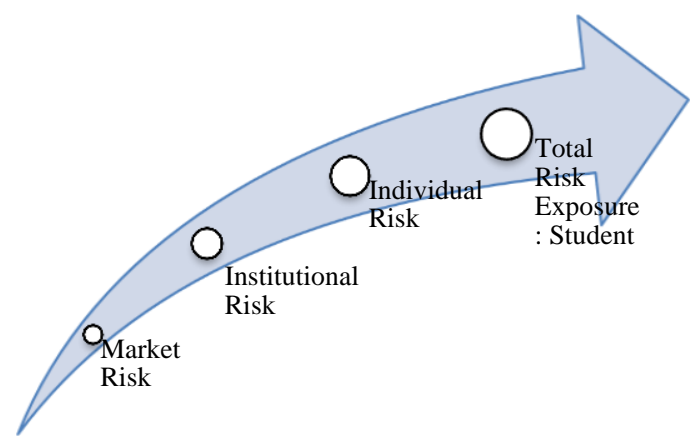

Figure 2. Conceptual model for student risk

Individuals bear highest risk while in school, the student still carries the highest probability of experiencing unemployment and poverty due to the lack of formalized education. A student at BC experiences a risk factor $179 \%$ and the CSUB student $149 \%$ over the non-PE individual. Once an associate degree is obtained the total risk for the individual is -
$2 \%$ under that of the non-PE individual. For a bachelor holding student their risk declines $-6 \%$ below a non-PE individual. It is important to recognize the substantial increase in risk between the individual choosing not to pursue PE and the student pursuing their PE (see Table 4).

While the student is in school, they are assuming all the economic risk related to the market, the institution and the individual without any of the rewards. Education is complicated because regardless of how many classes the student has accomplished there is nothing that provides a signal to the labor market the student possesses an asset until the degree is complete.

\section{Conclusion}

Federal, state and local agencies and institutions face their own challenges aligning the human capital produced by the local postsecondary institution with the labor market, and Kern County is no exception. The continual investigation into how to support the system which promotes individual and national economic growth should be a priority. It cannot be denied that this is a complicated time for postsecondary institutions. The labor market continues to change as technology does, often faster than the higher education can keep up with, while at the same time maintaining the academic rigor sacred to the academy. Both universities and community colleges are being asked to advance access to education, ensure students are obtaining a PE award, and make a living wage. Additionally, institutions of higher education are asked to, “...enhance individuals' core competencies and dispositions, such as the ability to think logically, the capacity to challenge the status quo, and the desire to develop sophisticated values for entry into the highly competitive labor market," [11]. The role of policymakers, leaders of postsecondary institutions, faculty and staff are critical to maintain stability at this juncture. The hope of this research is to support that endeavor.

This research has prompted important questions that need further analysis, but one that can be easily replicated in other regions. The algorithm above was intentionally left broad so different geographical areas can manipulate it as needed. Now that areas of vulnerability have been identified, it is left to the cooperative of the local region to investigate how to best support their constituents. The rigidity in which institutions of higher education function make it difficult to pivot academically when market demands change. There needs further investigation into whether broader degrees can be created which are more internally malleable, but still maintain the integrity and rigor that higher education values. It does not benefit the individual, institution or the economy when there is misalignment between the 
institution, which is the engine of human capital and market supply, and the local economy. Continued evaluation of a more robust labor market forecasting model would strengthen the synergy between the individual, institution and the local economy. When one link within the group weakens the affect is felt throughout.

\section{References}

[1] Ali, H. M. (2014). Modern portfolio theory: Is there any opportunity for real estate portfolio? Retrieved from: https://www.researchgate.net/publication/48267844.

[2] Anthony, P., Ross, S., \& Cheah, B. (2011). The college payoff: Education, occupations, lifetime earnings. Retrieved from ttps://www2.ed.gov/policy/highered/reg/hearulemaki ng/2011/collegepayoff.pdf.

[3] Baum, S., \& Payea, K. (2004). Education pays: The benefits of higher education for individuals and society. Washington, DC: College Board.

[4] Becker, G. (1994). Human capital: a theoretical and empirical analysis, with special reference to education (3rd ed.). Chicago, IL: The University of Chicago Press.

[5] Bellas, M. L. (2001). Investment in higher education: Do labor market opportunities differ by age of recent college graduates? Research in Higher Education, 42(1), 1-25.

[6] Brady, H., Hout, M., \& Stiles, J. (2005). Return on investment: Educational choices and demographic change in California's future. Berkeley, CA: Survey Research Center.

[7] California Community Colleges. (2019). Student Centered Funding Formula. Retrieved from https://www cccco.edu/About-Us/Chancellors-Office/Divisions/College -Finance-and-Facilities-Planning/Student-Centered-Fundin g-Formula.

[8] Carnevale, A. P., Cheah, B., \& Hanson, A. R. (2015) The economic value of college majors. Washington, DC: The Center on Education and the Workforce. Retrieved from https://www.luminafoundation.org/files/resources/ economic-value-of-college-majors.pdf.

[9] Carnevale, A. P., Jayasundera, T., \& Hanson, A.R (2012). Five ways that pay along the way to the B.A Washington, DC: The Center on Education and the Workforce.

[10] Carnevale, A. P., Rose, S. J., \& Cheah, B. (2011). The college payoff: Education, occupation, and lifetime earnings. Washington, DC: The Center on Education and the Workforce. Retrieved from http://cew.georgetown.edu/ collegepayoff/.

[11] Chan R.Y. (2016). Understanding the Purpose of Higher Education: An Analysis of the Economic and Social Benefits for Completing a College Degree. Journal of Education Policy, Planning and Administration (JEPPA). 2016;6 (5):1-40
[12] Dynarski, M. (1994). Who defaults on student loans? Findings from the national postsecondary student aid study. Economics of Education Review, 13(1), 55-68.

[13] Federal Reserve Bank of New York. (2020). Household debt and credit report, 2019Q3. Retrieved from https://www .newyorkfed.org/microeconomics/hhdc.html.

[14] Federal Student Aid. (2018a). Collections. Retrieved from ttps://studentaid.ed.gov/sa/repay-loans/default/ collections

[15] Fincher, M. (2017). Debt profiles of model students: The projected debt of highly productive students and its economic impact, Journal of Student Financial Aid, 47(1), Article 4. Retrieved from: http://publications.nasfaa.org/jsfa /vol47/iss1/4

[16] Goldrick-Rab, S., Kelchen, R., \& Houle, J. (2014). The color of student debt: Implications of federal loan program reforms for Black students and Historically Black colleges and universities. Retrieved from https://news.education. wisc.edu/docs/WebDispenser/news-connections-pdf/thecol olorofstudentdebt-draft.pdf?sfvrsn=4.

[17] Greene, L. L. (1989). An economic analysis of student loan default. Educational Evaluation and Policy Analysis, 11 (1), 61-68.

[18] Gross, J., Cekic, O., Hossler, D., \& Hillman, N. (2010). What matters in student loan default: A Review of the research literature. Journal of Student Financial Aid, 39(1), 19-29.

[19] Harrast, S. A. (2004). Undergraduate borrowing: A study of debtor students and their ability to retire undergraduate loans. Journal of Student Financial Aid, 34(1), 21-37.

[20] Herr, E., \& Burt, L. (2005). Predicting student loan default for the University of

Texas at Austin. The Journal of Student Financial Aid, 35(2), 27-49.

[21] Houle, J. N. (2014). Disparities in debt: Parents' socioeconomic resources and young adult student loan debt. Sociology of Education, 87(1), 53-69.

[22] Ishitani, T., \& McKitrick, S. (2016). Are student loan default rates linked to institutional capacity? The Journal of Student Financial Aid, 46(1), 16-37.

[23] Kim, C., Tamborini, C. R., \& Sakamoto, A. (2015). Field of study in college and lifetime earnings in the United States. Sociology of Education, 88(4), 320-339.

[24] Oreopoulos, P., \& Petronijevic, U. (2013). Making college worth it: A review of the returns to higher education. Future of Children, 23(1), 41-65.

[25] National Center for Education Statistics [NCES] (2019). The Condition of Education 2019, Retrieved from https://nces.ed.gov/programs/coe/pdf/coe_cue.pdf. 
[26] Queenan, E. \& Street, Brian D. (2018). Supporting Academia and Economy: Facing the Student Loan Crisis. Cambridge Business \& Economics Conference.

[27] Steiner, M., \& Teszler, N. (2005). Multivariate analysis of student loan defaulters at Texas A\&M University. College Station, TX: Texas A\&M University.

[28] St. John, E. P. (2001). The impact of aid packages on educational choices: High tuition high loan and educational opportunity. NASFAA Journal of Student Financial Aid, 31(2), 35-54.

[29] Trostel, P. (2017). Beyond the college earnings premium. Way beyond. Retrieved from: http://falcon.lib. csub.edu:2048/login?url=http://search.ebscohost.com/login .aspx ?direct=true $\& \mathrm{db}=\mathrm{a} 9 \mathrm{~h} \& \mathrm{AN}=121434055 \&$ site $=$ ehost live.

[30] U.S. Census Bureau. (2018). Kern County educational attainment 2009-2014, S1501. Retrieved from https://www.census.gov/topics/education/educationalattainment/data/tables.html.

[31] Volkwein, J., \& Szelest, B. (1995). Individual and campus characteristics associated with student loan default. Research in Higher Education, 36(1), 41-72.

[32] Webber, K., \& Rogers, S. (2014). Student loan default: Do characteristics of four-year institutions contribute to the puzzle? Journal of Student Financial Aid, 44(2), 98-124.

[33] Wilms, W. W., Moore, R. W., \& Bolus, R. E., (1987) Whose fault is default? A study of the impact of student characteristics and institutional practices on guaranteed student loan default rates in California. Educational Evaluation and Policy Analysis, 9(1), 41-54. doi:10.2307/1164036.

[34] Woo, J. H. (2002). Factors affecting the probability of default: Student loans in California. Journal of Student Financial Aid, 32(2), 5-23. 